\title{
Morfologia externa de Thyridia psidii cetoides (Rosenberg \& Talbot) (Lepidoptera, Nymphalidae, Ithomiinae). II. Tórax e apêndices ${ }^{1}$
}

\author{
Jorge Manuel Saraiva Bizarro ${ }^{2}$, Mirna Martins Casagrande ${ }^{2} \&$ Olaf Hermann Hendrik Mielke ${ }^{2}$ \\ 1 Contribuição número 1362 do Departamento de Zoologia, Universidade Federal do Paraná. \\ 2 Departamento de Zoologia, Universidade Federal do Paraná. Caixa Postal 19020, 81531-980 Curitiba, Paraná, Brasil. \\ Bolsista do CNPq. E-mail: bizarro@xmail.com.br; mibras@ufpr.br; omhesp@ufpr.br
}

\begin{abstract}
External morphology of Thyridia psidii cetoides (Rosenberg \& Talbot). II. Thorax and appendages (Lepidoptera, Nymphalidae, Ithomiinae). A detailed study of the thoracic external morphology of both sexes of Thyridia psidii cetoides (Rosenberg \& Talbot, 1914) is presented. The studied material was obtained at the city's plant nursery "Horto Florestal de Curitiba", Paraná, Brazil; mainly by rearing eggs and larvae collected on Cyphomandra betacea (Canavilles) Sendtner, 1845 (Solanaceae). When possible, all the results obtained were compared with those already available in the literature concerning other Nymphalidae subfamilies morphology (Brassolinae, Morphinae, and Danainae); the most striking feature being the almost totally transparent lateral faces of the thoracic mesoscutum in both sexes.
\end{abstract}

KEY WORDS. Comparative morphology, Cyphomandra, Neotropical.

Entre as borboletas diurnas pertencentes a Papilionoidea, a família mais numerosa é Nymphalidae, que apesar de bem estabelecida taxonomicamente como um grupo "natural", nos níveis inferiores à categoria família a classificação não está isenta de controvérsia, estando longe de uma solução satisfatória.

Na seqüência de outros trabalhos relativos à morfologia de espécies da família Nymphalidae, esta é a segunda contribuição ao estudo da morfologia externa do adulto de Thyridia psidii cetoides (Rosenberg \& Talbot, 1914), um gênero basal de Ithomiinae, Mechanitini (Fox 1949, 1967, D'Almeida 1978, Mielke \& BRown 1979), visando o tórax e seus apêndices, em ambos os sexos.

Como termo de comparação usaram-se estudos morfológicos disponibilizados na literatura sobre o tórax e respectivos apêndices (Ehrlich 1958a, b, Casagrande 1979, Bilotta 1995), para espécies de Danainae, Brassolinae e Morphinae, respectivamente, já mencionadas na primeira contribuição (BIZARRo et al. 2003).

\section{MATERIAL E MÉTODOS}

A metodologia seguida foi idêntica à do estudo da cabeça (BizArro et al. 2003), quer quanto à nomenclatura empregada, obtenção e processamento do material, quer no que se refere às técnicas usadas. Seguiu-se o padrão descritivo e comparativo dos trabalhos já publicados para a família Nymphalidae: Danainae (Ehrlich 1958a, b), Brassolinae (CASAgrande 1979) e Morphinae (Billota 1995), com particular ênfase para as diferenças encontradas, pelo que se procurou usar a mesma nomenclatura desses artigos, excetuando as asas, num esforço de unificação de termos visando a facilitação de análises comparativas. Para as asas, usou-se Nielsen \& Common (1991).

Nas análises da morfologia e da venação alar, as asas inteiras foram destacadas cuidadosamente dos exemplares, lavadas em álcool a 70\%, para desengordurar, e imersas em uma solução de hipoclorito de sódio (água sanitária comum) até completa diafanização das escamas. Em seguida, foram novamente imersas em álcool a 70\% para bloqueio da reação do hipoclorito, secas e prensadas entre folhas de papel absorvente, montadas entre lâmina e lamínula, usando Euparal como meio.

Foram examinados e comparados machos e fêmeas, para a verificação do dimorfismo sexual, tendo sido desenhadas as estruturas dimórficas de ambos, quando pertinentes.

Salvo indicação, a escala de cada desenho representa $1 \mathrm{~mm}$.

\section{Morfologia do tórax}

$\mathrm{O}$ tórax articula-se com a cabeça mediante o esclerito cervical, descrito na parte I desta serie (BizArro et al. 2003), e divide-se em três segmentos distintos: protórax, mesotórax e metatórax.

Protórax (Figs 1-5). O menor dos três segmentos torácicos. É formado pelos escleritos abaixo descritos e as pernas protorácicas.

O pronoto tem a forma de um cálice de base posterior (Fig. 4), que se articula com o mesotórax, com dois prolonga-

Revista Brasileira de Zoologia 20 (3): 419-425, setembro 2003 


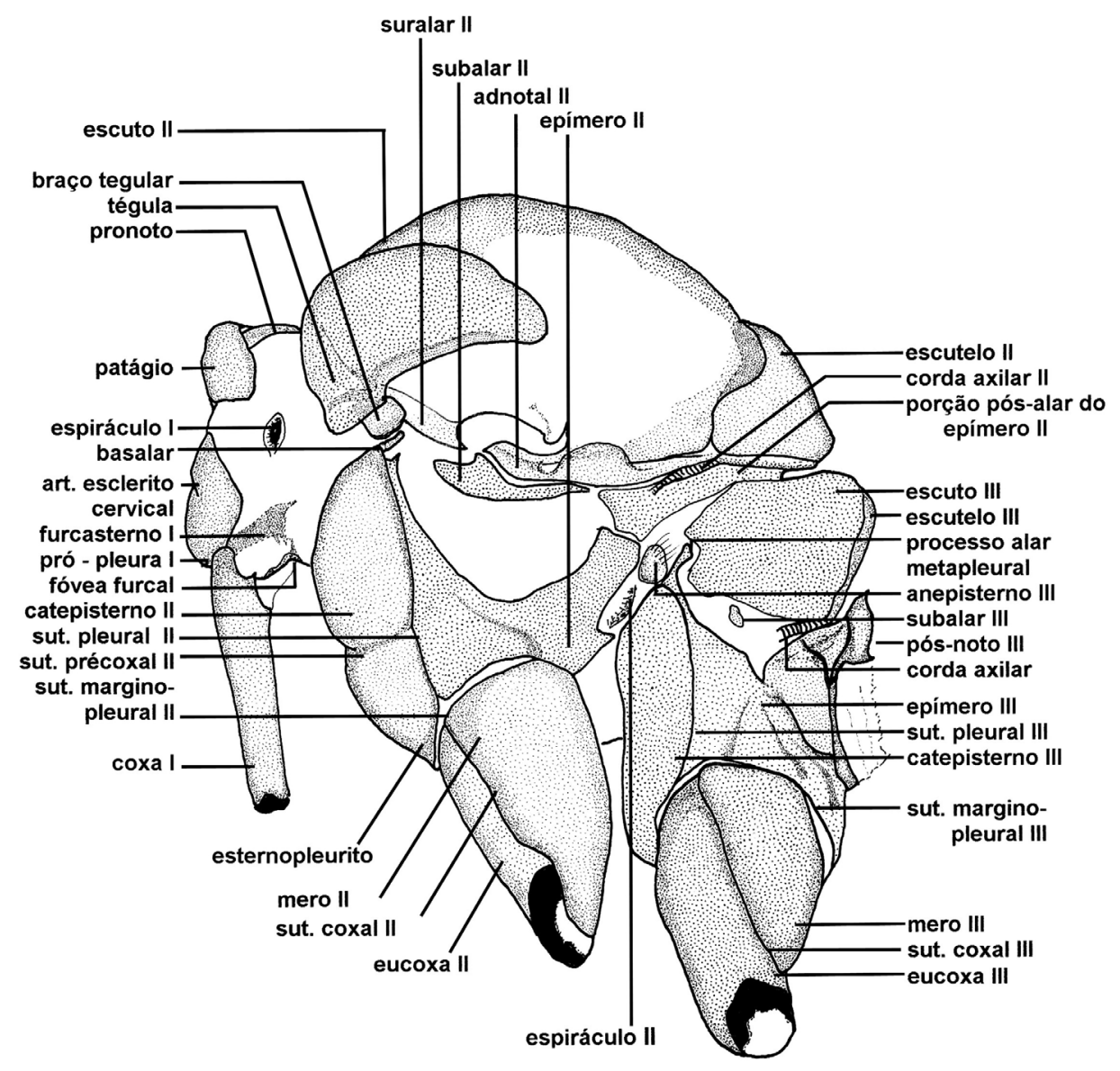

Figura 1. Thyridia psidii cetoides, tórax, vista lateral.

mentos triangulares laterais projetando-se para a base dos patágios. Difere de Caligo beltrao (CASAgRande 1979) e espécies de Morphinae (Billota 1995), pela ausência de um prolongamento mediano, o qual confere ao pronoto um aspecto em tridente nessas subfamílias. Outra diferença, quando comparada aos demais Nymphalidae, é a presença de um esclerito projetado na porção anterior do pronoto, em forma de " $\mathrm{Y}$ " invertido e ocupando todo o espaço entre a base dos patágios e o bordo dorsal dos escleritos cervicais (proscutum de Niculescu (1975, 1978), placa lateral do pronoto sensu EHRLich (1958a, b), o qual afirma (1958b) que todas as famílias de Hesperioidea e Papilionoidea apresentam esta estrutura, excetuando Pieridae, articulando-se inferiormente com o bordo ântero-dorsal das propleuras, com as quais completa um anel esclerotinizado que circunda perimetralmente o orifício posterior do forame cervical. Este esclerito forma um ângulo de $90^{\circ} \mathrm{com}$ o pronoto, unindo-se ao mesmo por um fino prolongamento pronotal em forma de barra que passa entre a base dos patágios (Fig. 5).

Patágio bem desenvolvido, ovalado, formando uma bolsa com maior eixo transversal, cuja base é membranosa e o dorso esclerotinizado, projetado em direção à base e mais evidente na face anterior do que na posterior.
A propleura articula ântero-dorsalmente com o esclerito cervical e dorsalmente com a placa lateral do pronoto, contornando a metade ventral do orifício cervical e delimitando no seu bordo inferior o alvéolo coxal, unindo-se ventralmente no sentido ântero-posterior por uma pequena comissura longitudinal, de largura sensivelmente idêntica à da coxa I: o discrime I. Na sua face lateral interna, uma pequena ponta em direção ao alvéolo coxal, a articulação pleural da coxa I, dificilmente visível em vista ventral.

O espiráculo I, presente na área membranosa imediatamente abaixo do patágio e acima da propleura, é circundado pelo peritrema, limitando uma fenda ovalada vertical, cujo contorno apresenta uma borda de escamas finas e longas.

O prosterno é formado, na linha mediana ventral, posterior ao alvéolo coxal, por um pequeno esclerito em forma de borboleta, o furcasterno, delimitado anteriormente pela membrana posterior do alvéolo coxal e póstero-ventralmente por um par de lamelas laterais que se unem em um esclerito fino e delgado em forma de " $\mathrm{Y}$ ", constituindo a furca; anteriormente a esta encontra-se a fóvea furcal.

A furca termina emitindo posteriormente um par de delgadas hastes, o espinasterno I, que divergem até se fundirem 

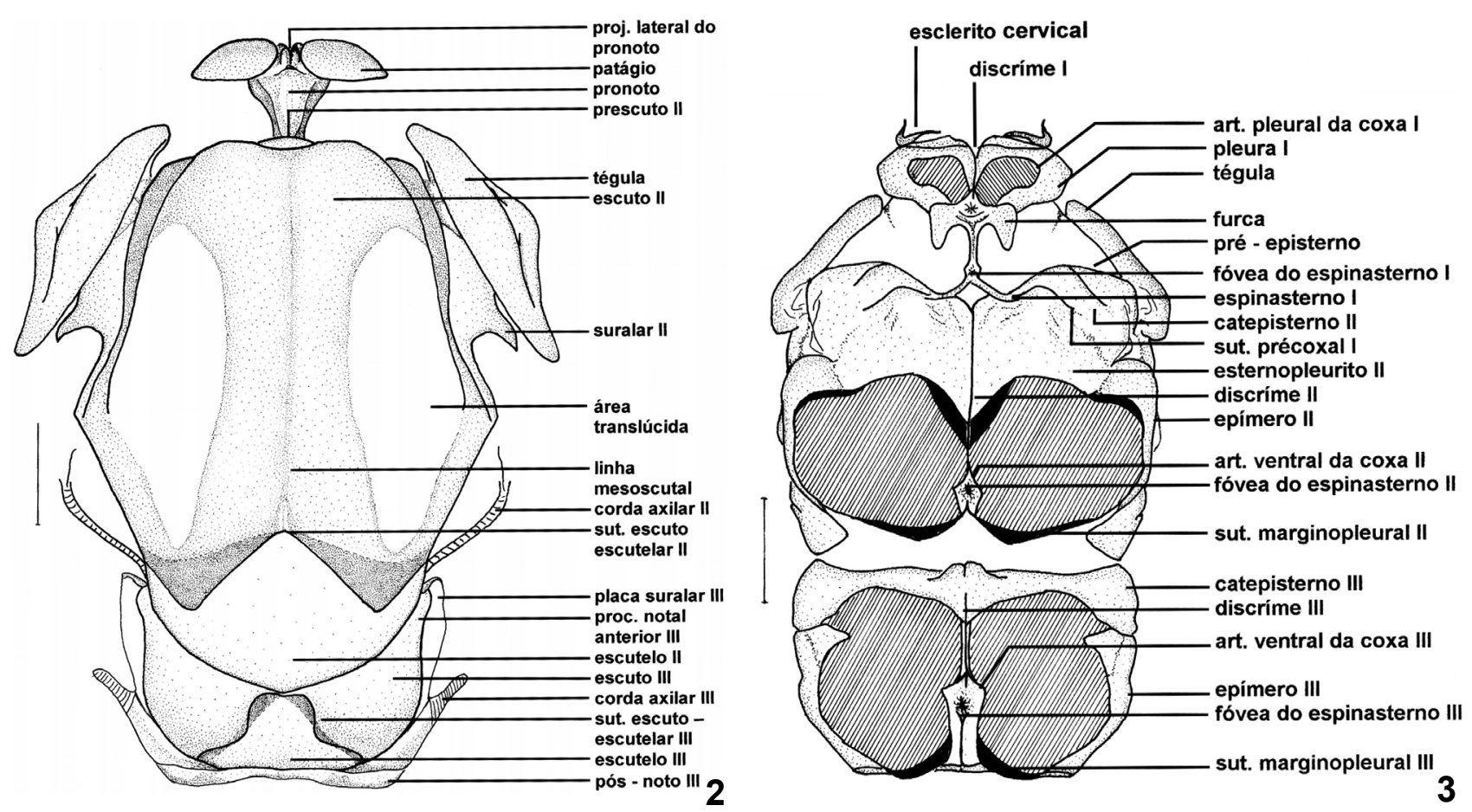

Figuras 2-3. Thyridia psidii cetoides, tórax: (2) vista dorsal; (3) vista ventral. (Art.) Articulação, (Proj.) projeção, (Proc.) processo, (Sut.) sutura.

lateralmente com o esternopleurito mesotorácico; na base destas encontra-se outra fóvea, penetrando no tórax mais profundamente que a furca: a fóvea do espinasterno I.

Mesotórax (Figs 1-3). Constitui o maior segmento torácico, formado pelos segmentos abaixo descritos, asas anteriores e pernas mesotorácicas.

Mesonoto dividido por suturas em prescuto, escuto, escutelo e pós-noto.

Prescuto II constituído por pequeno esclerito triangular com dois prolongamentos laterais em direção à base das tégulas, apenas visível em vista dorsal por ficar coberto pelo escuto II.

Escuto II é o maior esclerito, achatado lateralmente desde o terço médio até a extremidade posterior e fortemente convexo dorsalmente, formando uma crista. Apresenta a particularidade de ser escassamente esclerotinizado lateralmente, desde a extremidade da tégula até o bordo posterior, quase transparente; diferindo neste aspeto de Danaus plexippus (Енrцich 1958a), Caligo beltrao (CASAgRande 1979), espécies de Morphinae (Billota 1995) e outras espécies de Ithomiinae, onde todo o mesonoto é fortemente esclerotinizado. No restante, é identicamente esclerotinizado, não apresentando linha mesoescutal completa, sendo esta apenas esboçada no limite posterior do escuto.

Escutelo II é o segundo maior esclerito, de forma triangular, separado do escuto II pela sutura escuto-escutelar em forma de "W" devido ao prolongamento em profundidade da mesma.

Pós-noto II não visível dorsalmente, é esclerotinizado e funde-se lateralmente com a porção (ou prolongamento) pósalar do epimero II.
Mesopleura dividida lateralmente pela sutura pleural II, delimitando posteriormente o epimero II e anteriormente o episterno II, este dividido pela sutura pré-coxal incompleta em catepisterno II e esternopleurito, sendo o primeiro duas vezes mais longo que o segundo. Neste aspecto difere de Caligo beltrao (Casagrande 1979) e espécies de Morphinae (Billota 1995), onde ambos escleritos são de idêntico comprimento e separados por uma sutura nítida, aproximando-se de Danaus plexippus (EHRLICH 1958a) nas dimensões relativas, mas não na presença de sutura completa. Além destas diferenças, Ithomiinae difere na completa ausência do anepisterno II e pré-episterno, este último pouco nítido em Danaus plexippus (ЕнRцICH 1958b), mas bem desenvolvido em Caligo beltrao (CASAgRANDE 1979) e espécies de Morphinae (Billota 1995).

O catepisterno II apresenta margem anterior livre, é limitado pela sutura pré-episternal em Danaus plexippus (ЕнRцich 1958a), Caligo beltrao (CASAgRande 1979) e espécies de Morphinae (Billota 1995), onde o pré-episterno está presente, prolongando-se ventralmente até se articular com o espinasterno I anteriormente ao esternopleurito II, do qual fracamente se separa pela sutura pré-coxal.

Esternopleurito II limitado posteriormente pela sutura pleural II e ventralmente pela sutura marginopleural II que circunda o mero II e a eucoxa II, dirige-se ventralmente em direção ao espinasterno I, este localizado entre as coxas protorácicas e o catepisterno II, unindo-se no plano sagital formando o discrime II.

O epimero II é formado por dois escleritos: epimero propriamente dito e porção pós-alar do epimero, estando ausente

Revista Brasileira de Zoologia 20 (3): 419-425, setembro 2003 


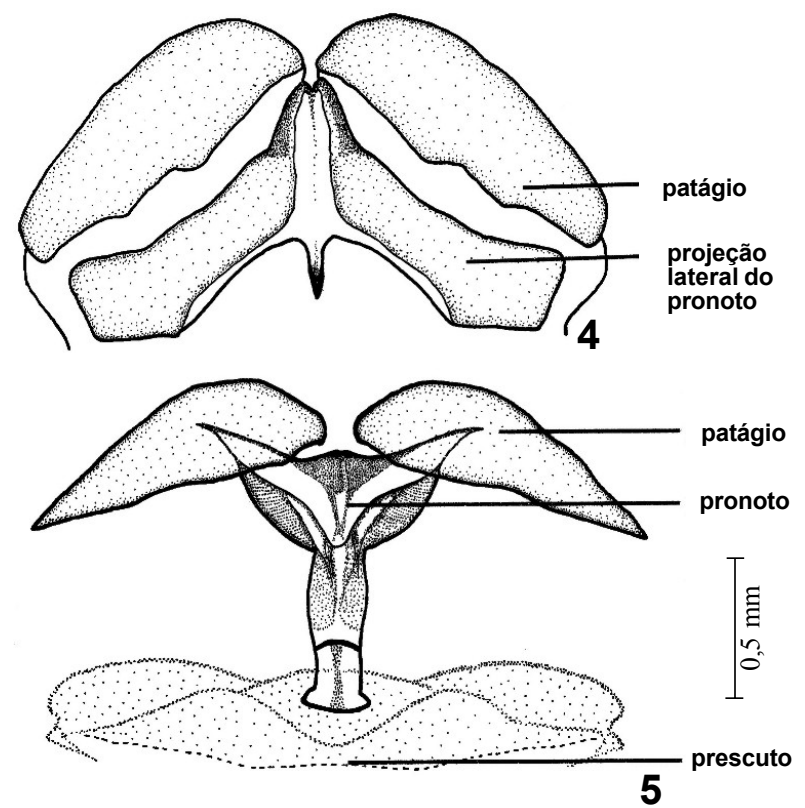

Figuras 4-5. Thyridia psidii cetoides, tórax: (4) projeções laterais do pronoto e patágios, vista anterior; (5) pronoto, vista dorsal.

o pré-epimero, o que não ocorre em Danaus plexippus (ЕHrLICH 1958a), Caligo beltrao (CASAGRANDe 1979) e espécies de Morphinae (Billota 1995).

Mesoesterno apresentando o discrime II, que se continua posteriormente pelo espinasterno II, pequeno esclerito que apresenta uma depressão central, a fóvea do espinasterno II e emite projeção lateral, a articulação ventral da coxa II.

Metatórax (Figs 1-3). Constitui o último segmento torácico, formado pelos escleritos abaixo descritos, asas e pernas metatorácicas.

O metanoto é nitidamente dividido em: escuto, escutelo e pós-noto.

Escuto III formado por dois lobos triangulares, incompletamente separados entre si pelo escutelo III, permanecendo unidos anteriormente por uma estreita ponte esclerotinizada e separado do escutelo III pela sutura escuto-escutelar III. A extremidade anterior do escuto III apresenta a placa suralar III, de limites mal definidos devido à ausência de uma sutura escutelar bem definida, na extremidade da qual se encontra o processo notal anterior III. Não se observa incisão escutal.

Escutelo III de formato triangular deformado pelo prolongamento da sutura escuto-escutelar III em profundidade, conferindo-lhe um aspecto quase trapezoidal. Lateral e posteriormente encontra-se a projeção mais evidente do escutelo III, o processo notal posterior III que termina na corda axilar III, a qual se dirige à base da asa posterior.

Pós-noto III forma uma barra estreita e transversa que encontra lateralmente a porção distal do epímero III.

Metapleura dividida pela sutura pleural III em episterno III e epimero III, sendo que esta sutura se dirige dorsalmente desde a sutura marginopleural III até ao processo alar metapleural, situado na porção superior do catepisterno III.
O episterno III é dividido pela sutura anepisternal em anepisterno III e catepisterno III. O anepisterno III é pequeno, isolado e de forma ovalar, apresentando um conjunto de cerdas no seu terço póstero-dorsal que se dirigem à base da asa posterior. Tais cerdas não são mencionadas nos trabalhos de ЕHRLICH (1958a), CASAGRANDE (1979) e Billota (1995), mas a sua presença em outras espécies pertencentes a famílias tão diversas como Limacodidae e Riodinidae leva a supor que podem estar presentes também em outras subfamílias de Nymphalidae. Entre o anepisterno III, catepisterno III e o epimero II, encontra-se o espiráculo II.

O catepisterno III constitui o restante da área esclerotinizada entre o anepisterno III e a coxa III, dirigindo-se ventralmente pelos lados da eucoxa III até se encontrar médio-ventralmente com o lado oposto, formando o discrime III.

Metasterno III formado pelo espinasterno III e constituído por uma dilatação retangular posterior do discrime III, com uma depressão central, a fóvea do espinasterno III. Anteriormente a esta, a projeção lateral triangular do discrime III forma a articulação ventral da coxa III que se une à projeção ventral do epimero III.

O epimero III contorna ventralmente todo o mero da coxa III, sendo subdividido por três fracas linhas, duas partindo da divisão com o mero que se perdem na região central do esclerito, e a terceira, mais nítida, separa o epimero da ponte pós-alar.

\section{Apêndices do tórax}

Asas (Figs 6-7). As asas de Thyridia psidii cetoides, mesmo após o tratamento com hipoclorito de sódio para diafanização, apresentam uma cor predominante acinzentada, vestígio da coloração preta, devido à presença de numerosas microtríquias negras dispersas na membrana alar. O mesmo tratamento aplicado a exemplares de Brassolinae, Morphinae ou Danainae deixa as asas completamente transparentes, sem vestigios do padrão de coloração original.

\section{Asa anterior (Fig. 6)}

Nos Ithomiinae, e particularmente em Thyridia psidii cetoides, o eixo longitudinal da asa anterior é o dobro do ânteroposterior, o ápice bem projetado externamente e a margem interna acentuadamente côncava na origem de $\mathrm{CuA}_{2}$, de forma que o torno é projetado caudalmente. Em Brassolinae e Morphinae, a asa anterior é triangular, de eixos longitudinal e ântero-posterior de dimensões mais próximas entre si; a margem externa reta ou ligeiramente ondulada; o ápice não se projeta mais externamente do que o torno; e a margem interna, se bem que sinuosa, não é acentuadamente côncava.

Venação. Subcosta (Sc) - uma das veias mais longas e espessas, originando-se na base, correndo paralelamente à margem costal e sofrendo uma inflexão súbita em direção à mesma, onde termina a $1 / 3$ do ápice.

Rádio ( $\mathrm{R}$ ) - com cinco ramos: $\mathrm{R}_{1}, \mathrm{R}_{2}, \mathrm{R}_{3}, \mathrm{R}_{4}$, e $\mathrm{R}_{5}$; inicia como uma veia única até aproximadamente metade de sua extensão e pouco antes do término da subcosta se ramifica em $\mathrm{R}_{1}$, que termina antes do ápice na margem costal, e no Setor Radial (Rs); este origina um segundo ramo, $\mathrm{R}_{2}$, um pouco mais à frente que corre paralelo a $R_{1}$ até terminar na margem costal. Prosseguindo em direção ao ápice, de Rs origina-se mais um ramo, $R_{3}$, a uma distância idêntica ao intervalo $R_{1}-R_{2}$ e continua até que, sensivelmente próximo ao ápice, se bifurca em dois 

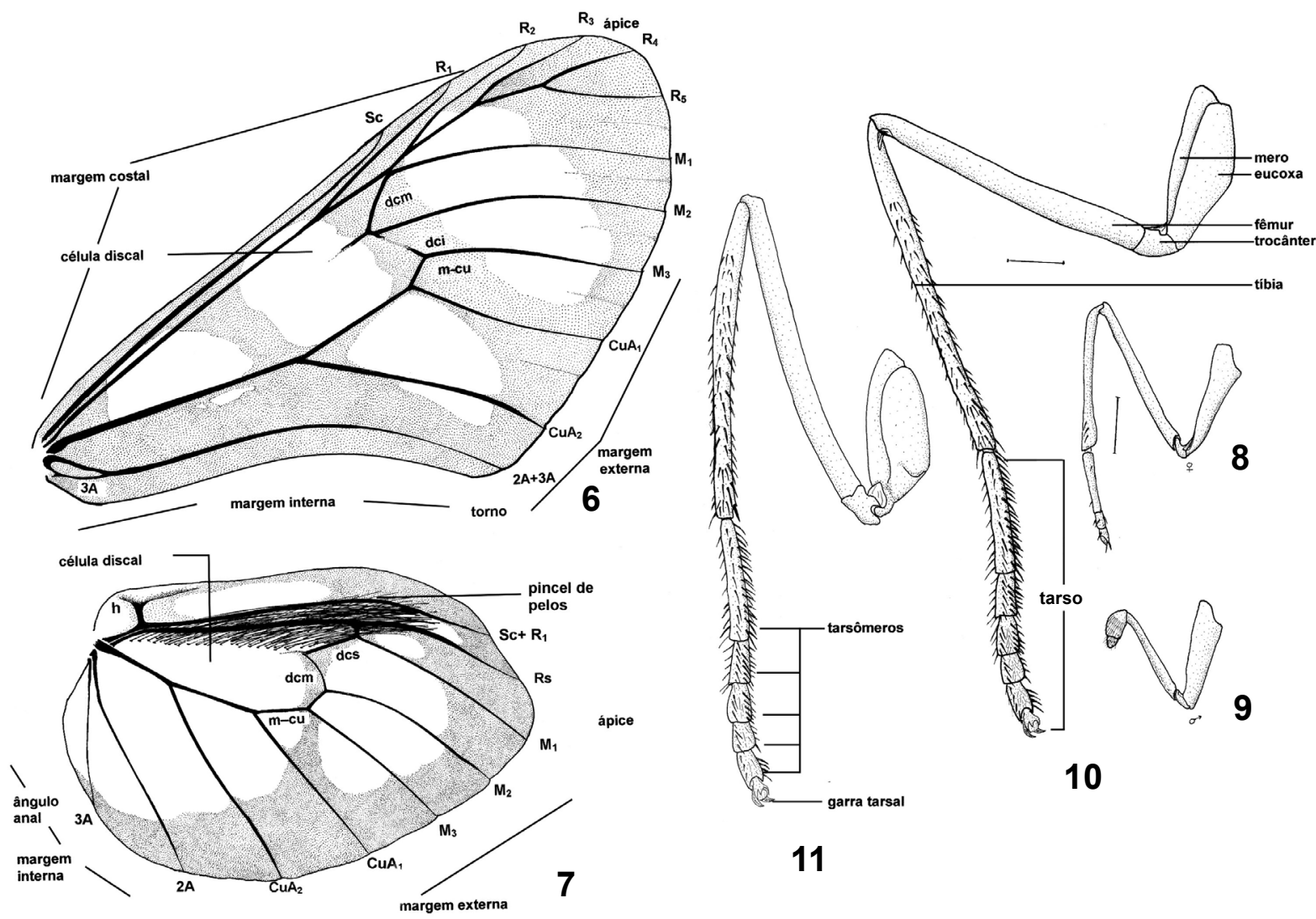

Figuras 6-11. Thyridia psidii cetoides. (6-7) Asas, vista dorsal: (6) asa anterior, (7) asa posterior (macho); (8-11) pernas, vista lateral esquerda: (8) protorácica da fêmea, (9) protorácica do macho, (10) mesotorácica, (11) metatorácica.

ramos de idêntico tamanho, $\mathrm{R}_{4}$ e $\mathrm{R}_{5}$, terminando a primeira no ápice e a segunda pouco depois deste, na margem externa. À exceção de $\mathrm{R}_{1}$, as restantes veias de Rs originam-se depois da célula discal.

Média (M) - presente na parte distal da célula discal, abaixo da emergência de $\mathrm{R}_{1}$, até as discocelulares, trifurcandose em $M_{1}, M_{2}$, e $M_{3}$, que se dirigem paralelas até a margem externa.

Cúbito Anterior $(\mathrm{CuA})$ - veia espessa na base, adelgaçando-se até se ramificar perto da metade da asa em $\mathrm{CuA}_{1}$ e $\mathrm{CuA}_{2}$. O Cúbito Posterior (CuP) está ausente em todos os Papilionoidea.

Anal (A) - 2A presente e paralela à margem interna da asa até alcançar o torno, $3 \mathrm{~A}$ isolada na base, fundindo-se à $2 \mathrm{~A}$ pouco depois do início desta.

A célula discal, limitada na porção anterior pela veia $\mathrm{R}$ e na posterior pela $\mathrm{CuA}_{2}$, é fechada por três veias transversais, duas disco-celulares: disco-celular mediana $(\mathrm{dcm})$ e disco-celular inferior (dci), sendo a disco-celular superior (dcs) ausente por anastomose de $M_{1}$ com Rs pouco antes da ramificação desta última em $\mathrm{R}_{2}$, e a médio-cubital (m-cu).

A principal diferença de Thyridia psidii cetoides com as outras subfamílias de Nymphalidae referidas previamente, excetuando Danainae (ACKERY \& VANE-WRIGHT 1984), em relação à asa anterior, é a ausência de dcs e a presença de um vestígio de $\mathrm{A}_{3}$ anastomosando-se com $\mathrm{A}_{2}$ logo na origem, formando uma pequena forquilha na base desta. Este último caráter ocorre esporadicamente em espécies de outras subfamílias não mencionadas acima.

\section{Asa posterior (Fig. 7)}

Em Ithomiinae varia de forma suficiente a constituir um bom caráter para distinguir tribos e gêneros (Fox 1956: 13, 1719; 1967: 6). Assim sendo, a descrição que segue é para Thyridia psidii cetoides. Além disso, ocorre dimorfismo sexual em dois caracteres: 1) presença de um pincel de finos e longos pelos odoríferos no macho, localizado junto à margem anterior da célula discal; 2) terminação de $\mathrm{Sc}+\mathrm{R}_{1}$; na fêmea é anterior ao ápice da asa, curvando-se anteriormente em direção à margem costal enquanto que no macho, corre paralela a esta, terminando próximo do ápice.

Asa posterior mais arredondada, quase elíptica, de eixo longitudinal ligeiramente maior que o ântero-posterior. A venação é reduzida; as veias Sc, R e CuA originando-se fundidas na base e separando-se pouco depois. Antes da ramificação do ramo anterior deste tronco comum, surge uma outra ramificação

Revista Brasileira de Zoologia 20 (3): 419-425, setembro 2003 


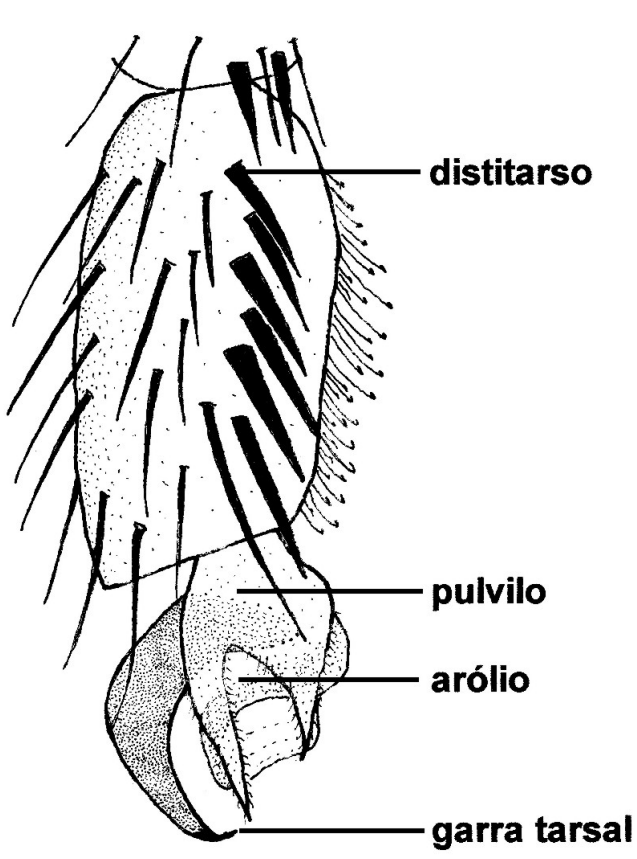

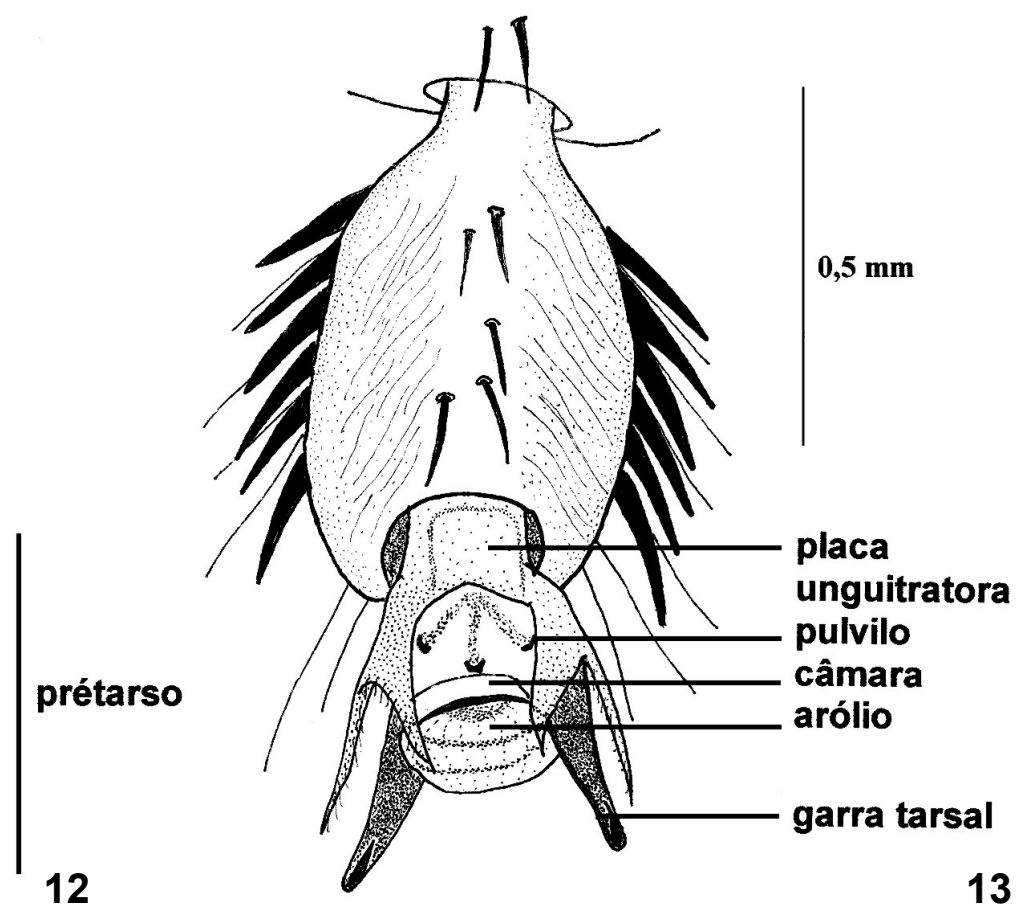

Figuras 12-13. Thyridia psidii cetoides, distitarso das pernas meso e metatorácicas: (12) vista lateral, (13) vista ventral.

proximal que se dirige à costa e se bifurca em $180^{\circ}$, a veia umeral (h), com ramos basal e distal, espessa na base, ausente na asa anterior, cuja finalidade é o suporte do ângulo umeral muito desenvolvido na asa posterior para o mecanismo de acoplamento das asas. Logo após esta ramificação, o ramo anterior da veia comum divide-se em dois, o anterior é a Subcosta fundida com $\mathrm{R}_{1}\left(\mathrm{Sc}+\mathrm{R}_{1}\right)$ que se dirige à margem externa sem ramificações, e o posterior, Setor Radial (Rs), diverge da anterior, sem ramificarse, até alcançar a margem externa, imediatamente antes do ápice. A Média (M) ausente na célula discal, ramifica-se tal como na asa anterior em $\mathrm{M}_{1}, \mathrm{M}_{2}, \mathrm{M}_{3}$, correndo paralelas em direção à margem externa onde terminam. O Cúbito anterior $(\mathrm{CuA})$ ramifica-se em $\mathrm{CuA}_{1}$ e $\mathrm{CuA}_{2}$, paralelas até atingirem a margem externa. As duas Anais ( $2 \mathrm{~A} \mathrm{e} 3 \mathrm{~A}$ ), divergem muito entre si, sendo 2A mais longa e paralela à $\mathrm{CuA}_{2}$ e terminando na margem externa, enquanto $3 \mathrm{~A}$ tem metade do comprimento desta, terminando na margem interna onde delimita a prega anal da asa.

\section{Pernas (Figs 8-13)}

Perna protorácica marcadamente atrofiada, especialmente nos machos. Esta é uma característica de Nymphalidae. Contrariamente ao habitual nesta família, em que o tarso da perna protorácica do macho é atrofiado e o da fêmea geralmente com cinco tarsômeros, tal como constatado em Caligo beltrao (Casagrande 1979) e espécies de Morphinae (Billota 1995), Thyridia psidii cetoides discorda deste padrão ao apresentar apenas três tarsômeros na fêmea, aproximando-se de Danainae (EHRLich 1958a, ACKERY \& VANE-Wright 1984), cujo prótarso da fêmea possui quatro tarsômeros, constituindo-se em uma das sinapomorfias desta subfamília.
A coxa do primeiro par de pernas é cilíndrica, alongada, sem suturas e articula-se basalmente com a propleura. As coxas do segundo e terceiro pares constam de dois escleritos unidos medianamente por uma sutura longitudinal, a sutura coxal. $\mathrm{O}$ esclerito anterior, assim delimitado, é a eucoxa e o posterior o mero, ambos unidos ao tórax mediante a sutura marginopleural. No ápice da sutura coxal, tanto no meso como no metatórax, antes do epimero, um pequeno esclerito pouco perceptível, o basicoxito. A coxa articula-se com o trocânter, de comprimento idêntico ao do tarsômero distal, mediante pequena projeção ou apófise, sendo esta articulação mais simples na coxa protorácica.

O fêmur protorácico é maior que a tíbia, o meso é menor e o meta de igual tamanho. Tal como o trocânter e a coxa, não apresentam espinhos, articulando distalmente com as tíbias, estas com numerosos espinhos dispostos em fileiras mais numerosas na face interna, sem esporões tibiais.

A tíbia protorácica do macho é reduzida, as demais normais e articulando-se distalmente com os tarsos, estes subdivididos em cinco tarsômeros nas pernas meso e metatorácica e, na perna protorácica, três tarsômeros nas fêmeas, com dois ou três espinhos, e um no macho. Neste último, o conjunto da tíbia e tarso forma uma campânula coberta por finas cerdas e escamas brancas. Nas pernas meso e metatorácicas, todas as superfícies dorsal e ventral dos tarsômeros são cobertas por espinhos, sendo o comprimento do primeiro tarsômero idêntico ao somatório dos quatro últimos. Além dos espinhos, observase a presença de finas cerdas transparentes na face ventral do terceiro, quarto e quinto tarsômeros das pernas meso e metatorácica; mais abundantes na fêmea que no macho, e na perna 
metatorácica que na mesotorácica. O tarsômero distal, distitarso, articula-se com o pré-tarso, encontrado em todas as pernas à exceção da protorácica do macho, que possui longas e finas cerdas na região distal da face externa e fileira de fortes espinhos na face interna, ladeando um tufo de cerdas transparentes.

\section{REFERÊNCIAS BIBLIOGRÁFICAS}

ACKeRY, P.R. \& R.I. VANE-Right. 1984. Milkweed butterflies. Their cladistics and biology. Being an account of the natural history of the Danainae, a subfamily of the Nymphalidae, Lepidoptera. British Museum (Natural History), London, Comstock Publishing Associates, Cornell University Press, $\mathrm{X}+425 \mathrm{p}$.

BiLotTa, I.G. 1995. Morfologia comparada do tórax das espécies sulbrasileiras de Morphinae (Lepidoptera, Nymphalidae). Revista Brasileira de Zoologia, Curitiba, 11 (4): 691-713.

Bizarro, J.S.; M.M. Casagrande \& O.H.H. MielKe. 2003. Morfologia externa de Thyridia psidii cetoides (Rosenberg \& Talbot) (Lepidoptera, Nymphalidae, Ithomiinae). I. Cabeça e Apêndices. Revista Brasileira de Zoologia, Curitiba, 20 (2): 279-284.

Brown JR., K.S. \& A.V. Freitas. 1994. Juvenile stages of Ithomiinae: Overview and systematics (Lepidoptera: Nymphalidae). Tropical Lepidoptera, Gainesville, 5 (1): 9-20.

Casagrande, M.M. 1979. Sobre Caligo beltrao (Illiger). III: Morfologia externa do adulto - tórax. (Lepidoptera, Satyridae, Brassolinae). Revista Brasileira de Biologia, Rio de Janeiro, 39 (2): 347-355.

D'Almeida, R.F. 1978. Catálogo dos Ithomiidae Americanos (Lepidoptera). Curitiba, Centro de Recursos Audiovisuais, Universidade Federal do Paraná, IV+405p.
EHRLICH, P.R. 1958a. The integumental anatomy of the monarch butterfly Danaus plexippus L. (Lepidoptera - Danaidae). The University of Kansas Science Bulletin, Lawrence, 38: 13151349.

. 1958b. The comparative morphology, phylogeny and higher classification of the butterflies. The University of Kansas Science Bulletin, Lawrence, 39: 305-370.

Fox, R.M. 1949. The evolution and systematics of the Ithomiidae (Lepidoptera). University of Pittsburgh Bulletin, 45 (8): 36-47.

. 1956. A monograph of the Ithomiidae (Lepidoptera). Part I. Bulletin of the American Museum of Natural History, New York, 111: 1-76.

. 1967. A monograph of the Ithomiidae (Lepidoptera). Part III, the tribe Mechanitini, Fox. Memoirs of the American Entomology Society, Philadelphia, 22: 1-190.

MielKe, O.H.H. \& K.S. BRown Jr. 1979. Suplemento ao Catálogo dos Ithomiidae Americanos (Lepidoptera) de Romualdo Ferreira d'Almeida (Nymphalidae: Ithomiinae). Centro de Recursos Audiovisuais, Universidade Federal do Paraná, Curitiba, VII+216p.

NiculesCu, E.V. 1975. L'exosquelette prothoracique et mesothoracique des Riodinidae (Lepidoptera). Bulletin et Annales de la Société royale entomologique de Belgique, Bruxeles, 111: $152-162$.

. 1978. L'exosquelette thoracique chez les Hesperiidae. Deutsche entomologische Zeitschrift (NF), Berlin, 25 (IIII): 205-210.

Nielsen, E.S. \& I.F.B. Common. 1991. Lepidoptera, p. 765-866. In: CSIRO (Ed.). The Insects of Australia. Carlton, Melbourne University Press, 1137p.

Recebido em 26.IX.2002; aceito em 07.VIII.2003. 